\title{
“Коммуникационный поворот” в истории России раннего Нового времени
}

\author{
The "Communicative Turn" \\ in Early Modern Russian History
}

\author{
Глеб Казаков \\ Университет им. Юстуса-Либиха в Гисене \\ Gleb Kazakov \\ Justus-Liebig University of Gießen \\ gleb.kazakov@gmail.com
}

Simon Franklin and Katherine Bowers, eds., Information and Empire: Mechanisms of Communication in Russia, 1600-1850, Cambridge: Open Book Publishers, 2017. 444 p. ISBN 9781783743735 .

Исследования принципов распространения информации и информационных сетей уже давно заняли важную нишу в изучении истории европейского раннего Нового времени. Причем если вначале интерес исследователей привлекала преимущественно именно история книгопечатания как нового культурного феномена,' то сегодня в библиографии трудов по истории коммуникации присутствуют многочисленные исследования, посвященные и почтовым путям сообщения, $^{2}$ и переписке дипломатических агентов, ${ }^{3}$ и распространению новостей и складыванию европейского информационного рынка в целом. ${ }^{4} \mathrm{~B}$ последние 15 лет особым спросом пользуется история печатных периодических изданий - летучих листков, брошюр, газет и журналов XVI-XVIII вв. Такой пристальный интерес к изучению средств массовой информации раннего Нового времени во многом обусловлен появлением в арсенале историков новых технических возможностей, недоступных для прежних поколений. Проведенные за последние годы во многих странах Европы проекты по оцифровке и системной цифровой каталогизации газет и других периодических печатных изданий безусловно позволили достичь нового уровня в обработке, анализе и обобщении данных о циркуляции информации в раннее Новое время. ${ }^{5}$

\footnotetext{
${ }^{1}$ См. классическую публикацию: Elizabeth L. Eisenstein, The Printing Revolution in Early Modern Europe (Cambridge: Cambridge University Press, 1983).

${ }^{2}$ Wolfgang Behringer, Im Zeichen des Merkur: Reichspost und Kommunikationsrevolution in der Frühen Neuzeit (Göttingen: Vandenhoeck \& Ruprecht, 2003).

${ }^{3}$ См., например, исследование о коммуникационной сети шведских дипломатов XVII в.: Heiko Droste, Im Dienst der Krone: schwedische Diplomaten im 17. Jahrhundert (Berlin: Lit Verlag, 2006).

${ }^{4}$ Andrew Pettegree, The Invention of the News: How the World Came to Know About Itself (New Haven: Yale University Press, 2014).

${ }^{5}$ Можно привести несколько примеров проектов оцифровки. Немецкие газеты XVII в. оцифрованы в рамках проекта “Zeitungen des 17. Jahrhunderts," проведенного государственной и университетской библиотекой Бремена (Staats- und Universitätsbibliothek Bremen) в 2013-2015 гг.
} 
Все вышесказанное относится, однако, к изучению истории коммуникации в странах Западной, Южной, Центральной и в несколько меньшей степени Северной Европы. Исследование коммуникационных механизмов и информационных сетей в рамках истории Российской империи безусловно только проходит стадию зарождения как отдельного направления. Причем если определенным темах, как, например, истории функционирования центральных приказов или составления вестей-курантов, уже посвящено солидное количество работ, то попытки синтеза материала, широкого взгляда на проблему до сих пор практически не предпринимались. Именно эту лакуну старается заполнить сборник статей, изданный американской исследовательницей Кэтрин Боуэрс (Katherine Bowers) и английским специалистом по истории Древней Руси Саймоном Франклиным (Simon Franklin) на основе материалов конференции, проведенной в Кэмбридже в 2014 году. Уже в самом заглавии книги “Информация и империя. Механизмы коммуникации в России, 1600-1850 гг." намечен главный вопрос, который призван объединить собранные статьи: “как растущее и развивающееся государство получало информацию о самом себе - о своей физической и социальной географии, об экономических процессах?” (с. 15). Связующим звеном оказывается, таким образом, понятие империи, государства, управляемого из имперского центра. Уже в предисловии редакторы сборника оговаривают, что внутри государства можно различить два направления коммуникационных потоков. Первое условно охарактеризовано как “вертикальное" - это коммуникация с управляющим центром, с государственными структурами. Второе направление - это “горизонтальная” коммуникация внутри государства между его жителями (с. 11). Боуэрс и Франклин признают, что тексты сборника преимущественно рассказывают о “вертикальной” коммуникации, а значит в роли главного участника коммуникационных процессов выступают государственные структуры Российской империи.

Очерчивая хронологические рамки сборника редакторы следуют получившему в последнее время признание, особенно в американской историографии, подходу, объединяющему историю Московской Руси и период Петербургской империи в единую "раннемодерную" эпоху российской истории. ${ }^{6}$ Верхней границей исследования, таким образом, оказывается период великих реформ середины XIX в., в то время как нижняя граница оказывается оговорена довольно смутно. Так, практически вне рассмотрения оказывается все XVI столетие, несмотря на появление именно в середине этого века в Московской Руси книгопечатания и установление первых тесных контактов с западноевропейскими державами. Собранные в рамках единого сборника статьи специалистов по XVII и XVIII вв. совместно рисуют картину эволюции механизмов коммуникации внутри

Оцифрованные выпуски нидерландских газет доступны онлайн на сайте проекта Delpher, cм. https://www.delpher.nl/nl/kranten. Выпуски французской La Gazette за XVII в. можно найти на сайте проекта Gallica - ведущей цифровой библиотеки Франции.

${ }^{6}$ См. разбор аргументов в пользу определения хронологических рамок истории России раннего Нового времени с 1500 г. по 1800 г. в: Donald Ostrowski, “The End of Muscovy: The Case for circa 18oo," Slavic Review, vol. 69, no. 2 (2010): 426-438; Nancy Shields Kollmann, The Russian Empire, 1450-1801 (Oxford: Oxford University Press, 2017). 
растущей российской империи, постепенно, но необратимо сталкивающейся с необходимостью технологической и культурной модернизации.

Содержание сборника разбито на пять тематических разделов: "Картографирование” (Map-making), “Почта и зарубежные новости” (International news and post), "Новости и почта в России" (News and post in Russia), "Коммуникация и государственные институты" (Institutional knowledge and communication) и “Информация на публичном обозрении” (Information and Public Display). При этом статьи внутри разделов сформированы неоднородно: в двух случаях читатель сталкивается с противопоставлением явлений XVII в. нововведениям века восемнадцатого. Так, в открывающем сборник разделе "Картографирование" Валери Кивельсон (Valerie Kivelson), автор известной монографии о картах в России XVII столетия, ${ }^{7}$ рассказывает в своей статье о русских картах XVII в. и приходит к выводу, что они хоть и могли бы показаться европейскому наблюдателю “примитивными,” вполне справлялись с возлагаемыми на них в Московской Руси задачами. Значительное место в статье отведено исследованию вопроса о трансфере информации, особенно информации о картах Сибири, ${ }^{8}$ и Кивельсон резюмирует, что несмотря на проводимую московскими властями политику секретности, обмен картографической информацией с Западом происходил не так-то уж и редко, пусть и преимущественно по неофициальным путям. При этом и само российское государство было заинтересовано в копировании и приобретении работ западных картографов. Статья Алексея Голубинского из того же раздела переносит читателя в XVIII век и рассказывает о технологических изменениях в российской картографической науке - о попытках приобрести за рубежом или произвести в России астролябии, так необходимые для точной фиксации координат внутри империи. Голубинский приходит к выводу, что к концу XVIII в. поставленная задача была выполнена и российское государство имело в резерве необходимое количество инструментов.

В разделе "Коммуникация и государственные институты" статьи также оказываются посвящены каждая своему столетию. Клэр Гриффин (Clare Griffin) исследует коммуникационные процессы и циркуляцию научного знания на примере работы Аптекарского приказа XVII в. и подчеркивает, что сфера взаимодействия данного приказа совсем не ограничивалась царским двором. К мнению экспертов-медиков приказа порой обращались и представители неэлиты, в определенных случаях отчеты сотрудников приказа могли посылаться и зарубежным дипломатическим партнерам. Статья Елены Корчминой посвящена системе сбора информации о налоговых поступлениях в Российской империи XVIII в. Исследовательница описывает хаос, который окружал процесс составления отчетности о налоговых сборах, и отмечает, что правительство в Петербурге, центре управления империей, имело крайне смутное представление о настоящем положении дел в финансах. Наконец, статья Екатерины Басаргиной сфокусирована на истории издания Журнала Министерства народного

\footnotetext{
${ }^{7}$ Valerie A. Kivelson, Cartographies of Tsardom: The Land and Its Meanings in Seventeenth-Century Russia (Ithaca, NY: Cornell University Press, 2006).

${ }^{8} \mathrm{O}$ трансфере информации и шпионаже на востоке российской империи см. также недавно вышедшую монографию: Gregory Afinogenov, Spies and Scholars: Chinese Secrets and Imperial Russia's Quest for World Power (Cambridge, MA: The Belknap Press of Harvard University Press, 2020).
} 
просвещения в 1834-1855 гг. Представляя Журнал как инструмент просветительской политики государства, Басаргина демонстрирует, насколько сильно судьба столь амбициозного проекта зависела от карьеры одного единственного человека - министра народного просвещения Сергея С. Уварова чья отставка в 1849 г. привела и к серьезному сокращению финансирования журнала.

Статьи из разделов “Новости и почта в России” и “Информация в публичном доступе” стараются, наоборот, не фокусироваться на отдельном столетии, а дать обзор выбранной теме на протяжении всего указанного в заглавии сборника периода. Джон Рэндольф (John Randolph) рассматривает историю почтовой службы, начиная с эпохи Московской Руси и доводя обзор до реформ Николая I, положивших конец существованию особого сословия ямщиков. Элисон Смит (Alison K. Smith) исследует историю появления и функционирования российских газет. Исследовательница демонстрирует, что именно российское государство было изначально заинтересовано в создании газет как средств циркуляции полезной для государства информации - законов и декретов, новостей о внешнеполитических успехах и т. д. Однако на практике, особенно с конца XVIII в. и особенно в провинции, газеты старались выйти за пределы государственного контроля и цензуры и стремились реагировать на информационные запросы общества, например, уделяя все больше и больше места разделам с неофициальными новостями и частными объявлениями. В разделе "Информация на публичном обозрении” Саймон Франклин рассматривает в своей статье историю “графосферы" в раннемодерной России 9 - сферы публичной демонстрации письменного слова, или, в определении автора: “суммы всех тех мест публичной жизни, где можно встретить надписи” (с. 341). Франклин начинает свой экскурс с XV в. и надписей на крестах, камнях, колоколах и других объектах публичного доступа. Основное внимание статьи, однако, сосредоточено на XVIII-XIX вв., т. е. периоде, когда создание “графосферы” - например, установка публичных монументов, столбов с надписями и т. п. - сначала являлось исключительно государственным проектом, а затем стало предметом и частной инициативы, например, через использование вывесок и объявлений у магазинов.

Наконец, статьи раздела “Почта и зарубежные новости”, написанные Даниэлом Bo (Daniel C. Waugh) и Ингрид Майер (Ingrid Maier), посвящены исключительно XVII столетию. Совместная статья обоих авторов посвящена обзору феномена т. н. курантов - переводов статей из европейской прессы на русский язык, создававшихся в московском Посольском приказе с 1620-х гг. по начало XVIII в. Во и Майер опираются как на свои предыдущие работы по данной теме, ${ }^{10}$ так и на уже ставшую классической для всех интересующихся вестями-курантами

\footnotetext{
${ }^{9}$ На эту же тематику см. недавно вышедшую монографию того же автора: Simon Franklin, The Russian Graphosphere, 1450-1850 (Cambridge: Cambridge University Press, 2019).

${ }^{10}$ Ingrid Maier and Daniel C. Waugh, "How Well Was Muscovy Connected with the World?" in Imperienvergleich. Beispiele und Ansätze aus osteuropäischer Perspektive. Festschrift für Andreas Kappeler, eds. Guido Hausmann and Angela Rustemeyer (Wiesbaden: Harrasowitz, 2009), 17-38; Ingrid Maier, "Presseberichte am Zarenhof im 17. Jahrhundert: Ein Beitrag zur Vorgeschichte der gedruckten Zeitung in Russland," Jahrbuch für Kommunikationsgeschichte, vol. 6 (2004): 103-129; Ингрид Майер, ред. Вести-Куранты. 1656 г., 166о-1662 г2., 1664-1670 г2. Ч. 2: Иностранные оригиналы крусским текстам (Москва: Языки славянских культур, 2008). (Ingrid Mayer, red. Vesti-Kuranty. 1656 g., 1660-1662 gg., 1664-167o gg. Ch. 2: Inostrannye originaly k russkim tekstam (Moscow: Iazyki slavianskikh kul'tur, 2008)).
} 
публикацию С. М. Шамина, ${ }^{11}$ и выносят свой вердикт, что куранты XVII в. безусловно не являлись “первой русской газетой," так как круг циркуляции данных рукописных переводов был ограничен преимущественно представителями московской правящей элиты. Вместе с тем историю создания курантов можно рассматривать как пример “европеизации” культурной жизни и системы коммуникации в России раннего Нового времени, так как создание переведенных на русский “дайджестов” европейской прессы безусловно копировало коммуникационные методы Западной Европы. В своей сольной статье Ингрид Майер поднимает вопрос об обратной коммуникации, о том, как новости из Московии попадали в западные газеты. В центре внимания оказывается эпизод с публикацией новостей о восстании Степана Разина в немецких газетах и брошюрах 1670-х гг., причем оказывается, что в трансфере информации за рубеж активно участвовало и само царское правительство, которое было заинтересовано в распространении сведений о поражении бунтовщиков и казни их лидера. ${ }^{12}$

Подводя итог, можно отметить, что материалы, собранные в рамках сборника, действительно охватывают широкий спектр тем: материальные предметы как носители информации и объекты коммуникации (карты и астролябии), функционирование почты, газеты как средства коммуникации, коммуникация внутри государственных структур, коммуникация в городском ландшафте. При этом многие статьи написаны именно в виде обзорных текстов, призванных не сосредотачивать все внимание на отдельном узком эпизоде, а дать общий экскурс в историю того или иного феномена. Нельзя не отметить такой важный факт, что сборник сам является примером общедоступной циркуляции научных знаний, т.к. был опубликован по принципу open access - его электронная версия находится в общем бесплатном доступе на сайте издателя Open Book Publishers. Вместе с тем все же сложно охарактеризовать данный сборник как всеобъемлющий справочник по коммуникации в России раннего Нового времени, ведь ряд крайне важных тем, как то признают и сами издатели в предисловии, никак не представлен в издании. Речь идет не только об истории книгопечатания, ${ }^{13}$ но и о такой важной сфере коммуникации, как дипломатические отношения и дипломатическая переписка. ${ }^{14}$ Из приказной системы XVII в. разобрана

\footnotetext{
${ }^{11}$ С. М. Шамин, Куранты XVII столетия. Европейская пресса в России и возникновение русской периодической печати (Москва \& Санкт-Петербург: Альянс-Архео, 2011). (S. M. Shamin, Kuranty XVII stoletiia. Evropeiskaia pressa v Rossii i vozniknovenie periodicheskoi pechati (Moscow and St. Petersburg: Al'ians-Arkheo, 2011).

${ }^{12}$ О новостях о казни С. Разина в немецкой периодике и участии царского правительства в передаче в западные медиа рисунка, изображающего плененного и казненного Разина см. также статью: Г. М. Казаков и Ингрид Майер, “Иностранные источники о казни Степана Разина. Новые документы из стокгольмского архива," Slověne = Словпне. International Journal of Slavic Studies, vol. 6, no. 2 (2017): 210-243 (G. M. Kazakov i Ingrid Maier, "Inostrannye istochniki o kazni Stepana Razina. Novye dokumenty iz stokgol'mskogo arkhiva," Slověne = Словпне. International Journal of Slavic Studies, vol. 6, no. 2 (2017): 210-243).

${ }^{13}$ Об истории книгопечатания в России XVIII в. см. классическую монографию: Gary Marker, Publishing, Printing, and the Origins of Intellectual Life in Russia, 1700-180o (Princeton, NJ: Princeton University Press, 1985).

${ }^{14}$ Из новейших исследований о коммуникационных связях и корреспонденции европейских дипломатов в России XVIII в. стоит отметить публикации немецких исследователей: Christian Steppan, Akteure am fremden Hof: politische Kommunikation und Repräsentation kaiserlicher Gesandter im Jahrzehnt des Wandels am russischen Hof (1720-1730) (Göttingen: V\&R unipress, 2016); Steven Müller-
} 
коммуникация только на примере Аптекарского приказа, вниманием обойден такой важный феномен вертикальной коммуникации, как составление челобитных и других “прошений во власть." В фокусе исследований авторов сборника оказывается, как уже упоминалось, именно коммуникация внутри властных структур и коммуникация между государством и обществом. В своей статье "Что являлось новостями и каким образом они распространялись в домодерной России?" (What Was News and How Was It Communicated in PreModern Russia?) Дэниел Во приводит несколько примеров горизонтальной коммуникации из частной переписки русских людей XVII в. и отмечает, что именно это направление исследований оставляет еще много открытых вопросов. В данной связи приятно отметить выход в 2018 г., т.е. через год после публикации рецензируемого сборника, монографии О. В. Новохатко о частной переписке в России XVII в., целиком посвященной как раз “горизонтальным интегративным тенденциям в русском обществе."15

Что касается нарратива, связывающего все статьи сборника воедино, предающего им общую направленность, некую путеводную нить, то здесь нужно отметить тезис о постепенной модернизации механизмов коммуникации в России XVII-XIX вв. Причем на материале статей четко прослеживаются два важных переломных момента в процессе этой модернизации. Первый связан с петровскими реформами: появление первой газеты, первых гражданских памятников, Академии наук и ее проектов. Второй расположен хронологически примерно в первой трети XIX в.: реформа почтовой системы, системы государственного управления, развитие “графосферы” в городском пространстве, газет. При этом важным ориентиром для России в данном процессе коммуникационной модернизации была Европа: тематика российскоевропейского культурного трансфера, передачи информации и заимствования технологий тем или иным образом затронута практически во всех статьях сборника. Наконец еще одним нарративом, почти неоговоренным издателями сборника в предисловии, но тем не менее прослеживаемым в ряде статей, является рассказ о постепенном вовлечении общества и частных лиц в процессы коммуникации - будь то появление первых частных газет, частных подрядчиков в почтовых пересылках или вывесок на частных магазинах.

Вопрос, остающийся у читателя после прочтения сборника, на который ни издатели, ни авторы статей не дают окончательного ответа: можно ли считать систему коммуникации, выстроенную государством внутри Российской империи, успешной? Ряд текстов, например статья Елены Корчминой об устройстве налоговых сборов, подводят к мысли, что скорее нет, что в коммуникации между имперским центром и периферией было слишком много задержек и недопониманий, что для эффективного функционирования системы просто не хватало ресурсов. Между тем сам факт успешного существования столь обширной империи на протяжении трех столетий заставляет не спешить с выводами. У издателей сборника, однако, безусловно не было задачи дать исчерпывающий

Uhrig: Wer regiert Russland? Das Aufbegehren des russischen Adels 1730 als vermeintliche Gefährdung der Monarchen Europas (Vienna \& Cologne: Böhlau Verlag, 2021).

${ }^{15}$ O. В. Новохатко, Россия, частная переписка XVII века (Москва: Памятники исторической мысли, 2018) (O. V. Novokhatko, Rossiia, chastnaia perepiska XVII veka (Moscow: Pamiatniki istoricheskoi mysli, 2018). 
ответ на этот вопрос, ведь, как уже подчеркивалось, изучение механизмов коммуникации и информационных трансферов в рамках истории России раннего Нового времени проходит лишь стадию становления. Как демонстрируют ссылки на литературу в сносках к данной рецензии, новые монографии в рамках данного исследовательского направления появляются в последние годы с вызывающей оптимизм частотой. 